\title{
A test of priority effect persistence in semi-natural grasslands through the removal of plant functional groups during community assembly
}

Kenny Helsen ${ }^{1,2^{*}} \mathbb{B}$, Martin Hermy ${ }^{3}$ and Olivier Honnay ${ }^{1}$

\begin{abstract}
Background: It is known that during plant community assembly, the early colonizing species can affect the establishment, growth or reproductive success of later arriving species, often resulting in unpredictable assembly outcomes. These so called 'priority effects' have recently been hypothesized to work through niche-based processes, with early colonizing species either inhibiting the colonization of other species of the same niche through niche preemption, or affecting the colonization success of species of different niches through niche modification. With most work on priority effects performed in controlled, short-term mesocosm experiments, we have little insight in how niche preemption and niche modification processes interact to shape the community composition of natural vegetations. In this study, we used a functional trait approach to identify potential niche-based priority effects in restored seminatural grasslands. More specifically, we imposed two treatments that strongly altered the community's functional trait composition; removal of all graminoid species and removal of all legume species, and we compared progressing assembly with unaltered control plots.
\end{abstract}

Results: Our results showed that niche preemption effects can be, to a limited extent, relieved by species removal. This relief was observed for competitive grasses and herbs, but not for smaller grassland species. Although competition effects acting within functional groups (niche preemption) occurred for graminoids, there were no such effects for legumes. The removal of legumes mainly affected functionally unrelated competitive species, likely through niche modification effects of nitrogen fixation. On the other hand, and contrary to our expectations, species removal was after 4 years almost completely compensated by recolonization of the same species set, suggesting that priority effects persist after species removal, possibly through soil legacy effects.

Conclusions: Our results show that both niche modification and niche preemption priority effects can act together in shaping community composition in a natural grassland system. Although small changes in species composition occurred, the removal of specific functional groups was almost completely compensated by recolonization of the same species. This suggests that once certain species get established, it might prove difficult to neutralize their effect on assembly outcome, since their imposed priority effects might act long after their removal.

Keywords: Emergent groups, Functional traits, Graminoids, Historical contingency, Legumes, Niche modification, Niche preemption, Plant-soil feedback, Size-asymmetric competition, Soil legacies

\footnotetext{
*Correspondence: kenny.helsen@ntnu.no

1 Plant Conservation and Population Biology, Department of Biology,

University of Leuven, Arenbergpark 31, 3001 Heverlee, Belgium

Full list of author information is available at the end of the article
} 


\section{Background}

Evidence continues to build that plant community assembly is rarely predictable at the species level, strongly challenging the traditional deterministic view of Clements [1] on succession [2,3]. Indeed, many studies have shown that assembly outcome is not solely determined by abiotic conditions, but is partly unpredictable, often resulting in multiple alternative end states of the assembly process [4-6]. These observations support the view of stochastic community assembly, first discussed by Gleason [7] and Diamond [8], where assembly is expected to be, up to a certain extent, contingent upon historical processes $[2,9]$. Historical contingency is hypothesized to affect assembly through multiple pathways, such as landuse legacies, interannual variation in (a)biotic conditions, historical landscape connectivity and priority effects [3, $10,11]$. In recent years, the importance of priority effects on plant assembly outcome has been given much attention [12-14]. Priority effects occur when early colonizing species inhibit or facilitate the establishment, growth or reproductive success of later arriving species, and are, for plants, hypothesized to be mainly caused either directly by size-asymmetric competition effects (inhibitory) $[15,16]$, or indirectly, by soil legacies (inhibitory or facilitative) $[12,17]$. In the latter case the priority effects are effectuated by changes in nutrient availability, soil microbial communities or the buildup of allelochemicals $[12,16]$. Soil legacies may persist for a long time after the causal species had disappeared from the community through the effects of plant-soil feedbacks [13, 17].

Even though priority effects are sometimes considered to be independent of species identity (neutral theory) $[10,18,19]$, an increasing number of studies on both asymmetric competition effects and plant-soil feedbacks strongly suggests the opposite, with certain species seemingly strongly affected by priority effects exerted by specific species, while others remain unaffected by the same initial species [20-24]. It has, for this reason, been argued that the occurrence and severity of both inhibitory and facilitative priority effects are often strongly dependent upon a species niche. Fukami [14] more specifically hypothesizes that priority effects can be governed by two alternate niche-based processes, namely niche preemption (inhibitory) and niche modification (either inhibitory or facilitative). According to this framework, priority effects governed by niche preemption processes, such as size-asymmetric competition, will only affect species within niches, while niche modification based priority effects, such as soil legacies, will primarily act across niches [14]. Support for this niche preemption hypothesis has been found during experimental assembly of bacterial communities, where strong priority effects, and hence multiple community states, only emerged when species pools contained species with great niche overlap [25], and for nectar-inhabiting microorganisms, where priority effect size was significantly related to the extent of niche overlap [26]. Although direct evidence for this hypothesis is currently lacking for plant assembly, it has been experimentally shown that-at least certain-plant communities are most inhibitive to invasion of new species with niche requirements that are similar to those of species already present in those communities [27, 28]. Other studies, however, suggest that this limiting similarity process might not be universally applicable for plant communities [29].

Nonetheless, since functional plant traits are considered to be directly linked to a species niche, the functional group identity of species will likely greatly improve our predictive ability of priority effect presence and strength. Indeed, priority effects through size-asymmetric competition are expected to only occur within functional groups [26], while soil legacies likely affect species both within and among functional groups [14]. This potential predictive power of functional traits has already been illustrated by the observation of deterministic assembly at the functional trait (niche) level, as opposed to contingent assembly at the species identity level [3032]. In these studies, the presence of multiple species with similar functional traits within a species pool are assumed to explain the occurrence of strong inhibitory priority effects at the species level through niche preemption, within each of the present niche spaces [33]. Nevertheless their potential, functional traits have only rarely been included as predictive variables in priority effect research during plant community assembly (but see $[23$, $34])$.

The current knowledge on priority effects has been mainly gained through largely controlled mesocosm experiments looking either only at size-asymmetric competition (e.g., $[10,19,24])$ or at soil legacies (e.g., [22, 34, $35]$ ). However, in natural systems, both inhibitory niche preemption and inhibitory or facilitative niche modification based priority effects may be simultaneously shaping community structures, making generalizations from these mesocosm experiments difficult [16]. Similarly, the priority effects observed in these mesocosm studies are usually surprisingly strong, likely because of optimal growing conditions and relatively short studied time scales (1-2 years after initial colonization) [10, 36]. Although little information is available on long-term priority effects, Hawkes et al. [22] have shown that experimental plant soil feedbacks can become increasingly negative for many species after 4 years. Two studies have furthermore observed indications of persistent priority effects at somewhat larger timescales (4-5 years) in grassland systems [32, 37]. A study of vernal pool plant 
communities in a more natural system, on the other hand, found the disappearance of priority effects after 7 years [20]. In conclusion, we can say that there is need for more in situ research to adequately quantify the importance of priority effects on long-term assembly progress and outcome in natural systems [19].

In this study, we want to fill part of this knowledge gap by evaluating potential priority effects at the functional trait level, using natural dry grasslands as a model system. More specifically, we evaluated small-scale plant community composition during the early stages of grassland development, following restoration practices. We imposed two treatments that severely altered the functional trait composition of the community; removal of all graminoid species and removal of all nitrogen fixating species (legumes). Additionally we also included a control treatment. The experiment was performed in four different restored semi-natural grasslands on the French-Belgian border, with four $5 \times 5 \mathrm{~m}$ replicates (plots) of each treatment in each grassland, and was followed up during four consecutive years. In this experiment, we expected graminoids to mainly impose local inhibitory niche preemption (competition) effects on the community, since graminoids are often highly competitive. Legumes on the other hand, are known to fixate nitrogen, thus altering soil nutrient content. Taking into account the relatively weak competitive abilities of the legume species in our study system, we hypothesized that legumes mainly impose local facilitative niche modification (soil legacy) effects on the community. By comparing the changes in the species composition of both the treatment functional groups (graminoids and legumes) and previously defined functional trait groups (emergent groups) among the three treatments, we tried to verify the following hypotheses:

1. Removal of graminoids will relief local inhibitory within-niche competition effects, resulting in the local colonization of species with the same functional trait set as the removed species (inhibitory niche preemption).

2. Removal of legumes will likely result in the local colonization of species adapted to high nutrient availability, thus resulting in the colonization of species with a different functional trait set as the removed legume species (facilitative niche modification).

3. Small-scale plot level changes in the community composition caused by the graminoids and legumes will still be visible after 4 years, through newly enforced priority effects of secondary colonized species.

\section{Methods}

\section{Study area}

The study was performed in four recently restored seminatural grassland patches, on the French-Belgian border (c. $50^{\circ} \mathrm{N}, 4.5^{\circ} \mathrm{E}$ ). These patches are part of four larger, isolated grassland fragments, which are embedded in a matrix consisting of a mixture of arable land and forests, surrounded by several other grassland fragments. The four studied grassland patches were all restored from forest or shrub encroachment in 2007, and are adjacent to mature grassland within the grassland fragment. Initial restoration practices consisted of the complete removal of all aboveground vegetation and litter, after which spontaneous colonization of the bare soil was allowed. Soil characteristics were not directly altered, nor were plant species or seeds deliberately introduced to the restored sites. The follow up management of these grasslands consists of annual grazing by a migratory sheep flock. The grazing management prevents domination by woody species and also allows the dispersal of plant species through zoochory. Note that this setup strongly reduces any effect of dispersal limitation at the plot level, since all plots are imbedded within one of four larger grassland patches.

\section{Experimental design}

To test for possible priority effects on grassland community assembly we used an experimental design consisting of three (functional identity) conditions. More specifically, these conditions consisted of the removal of all nitrogen fixation species or Fabaceae (condition L; legumes), removal of all Poaceaea, Cyperaceae and Juncaceae species (condition G; graminoids) and a standard condition with no manipulation of assembly (condition $C$; control). Manipulation for all conditions was performed within separate $5 \times 5 \mathrm{~m}$ plots by carefully applying very small and targeted amounts of glyphosphate to the target species in the summer of 2010 (July), with a follow up in September of 2010 to remove the dead aboveground biomass and to make sure all treatment species were successfully killed. This set-up was replicated over four grassland patches. Each treatment was spatially randomly replicated for four times within each grassland patch, adding up to a total of $48,5 \times 5 \mathrm{~m}$ plots. After initial manipulation in 2010, these communities were allowed to follow spontaneous community assembly. Species composition and abundance (\% cover) was collected for all plants (Tracheophytes) in each plot during the summer (July) of four consecutive years (2010-2013), with the 2010 data collected before initial manipulation. This field study was performed on public land. As our manipulations did not directly involve, nor did indirectly affect any endangered species we did not require special permission. The full plots $\times$ species dataset can be found at [38].

\section{Functional traits and emergent groups}

For the evaluation of functional trait patterns, we used the emergent groups (EGs) that were defined by Helsen 
et al. [39] for the species pool of similar dry semi-natural grasslands. More precisely, Helsen et al. [39] delineated seven EGs based on twenty-eight functional plant traits using a minimum variance clustering method based on Gower's similarity (Table 1). These traits were selected based on their relevance for community assembly, through their effects on species dispersal, establishment and persistence (cf. [40]) and were obtained from different databases (Additional file 1). Additionally, we calculated the community weighted means (CWM, as defined by [41]) for the three binary functional traits (thus the weighted proportions): nitrogen fixation, graminoid morphology and clonality. The values for these three functional traits were collected from the Ecoflora and Biolflor databases $[42,43]$.

\section{Diversity metrics}

Species richness (S) and Pielou's evenness index (E) were calculated for each plot, including all species, generalist species only, and specialist species only. Specialist species were defined as species confined to dry semi-natural grasslands in Belgium [44, 45] (Additional file 2). Species richness and total plant cover (\%) were calculated twice for each EG separately, once including all species within each EG, and once excluding all treatment species (all Fabaceae, Poaceae, Cyperaceae and Juncaceae species).

\section{Species identity turnover}

To evaluate changes in the species composition within treatment functional groups (graminoids and legumes), we quantified the species replacement of both species groups between the first (pre-treatment, year 0) and last year (year 3) of the experiment. Comparing species replacement of both species groups among the different treatments allows better insight in how priority effects are shaping the community composition. Species replacement was calculated as the 'relativized species replacement' $R_{\text {rel }}$ based on presence-absence data [46] and as the 'relativized abundance replacement' ${ }^{2} R_{\text {rel }}$ based on abundance data [47] for both treatment functional groups separately, resulting in four species replacement measures.

\section{Statistical analysis}

Differences in overall species diversity and species diversity of individual emergent groups between the three treatments were assessed using repeated measures linear mixed models (RMLMMs). More specifically, we constructed a separate RMLMM for each diversity metric as a dependent variable, including treatment, time (year) and the interaction between time and treatment as fixed factors, grassland identity as a random factor ('variance components' covariance type) and time (year) as a random repeated measure ('unstructured' covariance type). The model included both fixed and random (ID) intercepts and was based on restricted maximum likelihood (REML). Analogous RMLMMs were constructed for the CWM of nitrogen fixation, graminoid morphology and clonality. Prior to statistical analyses, several response variables were transformed to obtain normal distributions of the model residuals. In particular, all three measures of evenness (for all species, specialists and generalists) and the clonality CWM were squared, the cover of EG 1 was log transformed and we took the square root for the nitrogen fixation CWM, graminoid morphology CWM and the cover of all individual EGs (except EG 1) and total cover.

Among-treatment differences in species replacement within treatment functional groups were tested using linear mixed models (LMMs). More precisely, we

Table 1 Overview of the emergent groups (EGs) as defined in Helsen et al. [39]

\begin{tabular}{|c|c|c|}
\hline Emergent group & Group name & Characteristics \\
\hline 1 & Megaphanerophytes & $\begin{array}{l}\text { Long lived, shade-tolerant species, early flowering, wind pollinators, large seeds, transient seed } \\
\text { bank, allogamous, anemo- and dysochores. Species of nutrient rich soils }\end{array}$ \\
\hline 2 & Forest/shrub species & $\begin{array}{l}\text { Long lived, shade-tolerant herbaceous and woody (understory) species, insect pollinated, } \\
\text { transient seed bank, mixed mating system, few and heavy seeds, dysochores, large leaves. } \\
\text { Species of nutrient rich soils, shade tolerant }\end{array}$ \\
\hline 3 & Orchids & Many, small seeds, mycorrhiza-dependent \\
\hline 4 & Small grassland herbs & $\begin{array}{l}\text { Allogamous, shade intolerant, small herbs, autochores and zoochores, nitrogen fixators, semi- } \\
\text { rosette species, specialists }\end{array}$ \\
\hline 5 & Large herbs and grasses & $\begin{array}{l}\text { Semi-rosette species, late flowering, large seeds, large species, large leaves, hemero- and } \\
\text { zoochores, competitives. Species of nutrient rich soils }\end{array}$ \\
\hline 6 & Sedges and shallow soil specialists & $\begin{array}{l}\text { Mixed mating system, long seedbank longevity, small and light seeds, auto- and anemochores, } \\
\text { mycorrhiza-independent }\end{array}$ \\
\hline 7 & Annuals & Early flowering, autogamous, short-lived, small seeds and plants, zoochores, ruderals \\
\hline
\end{tabular}

For every group the name and typical functional trait values (characteristics) are given. Note that EG 3 (orchids) was not used in this study since too few species of this group were observed 
constructed a separate LMM for each of the four calculated species replacement measures $\left(R_{\text {rel }}\right.$ and $\left.{ }^{a} R_{\text {rel }}\right)$ as a dependent variable, including treatment as a fixed factor and grassland identity as a random factor ('variance components' covariance type). The model included a fixed intercept and was based on restricted maximum likelihood (REML). Semi-partial $R_{\beta}^{2}$ coefficients were calculated for each covariate in all performed RMLMMs and LMMs, using the method of Edwards et al. [48].

\section{Results}

Total species richness increased through time for all plots, independent of the treatment. This increase through time was found to be mainly driven by a strong increase in specialist species, with a decrease of generalist species (Table 2; Fig. 1a). The total evenness per plot, on the other hand, decreased through time, a pattern also observed for specialist species, and, although less pronounced, for generalist species (Fig. 1b). Evenness of specialist species was also affected by treatment, with a higher evenness in the $\mathrm{G}$ treatment ( $\beta$ G, Table 2$)$. Total vegetation cover per plot strongly increased through time, but was reduced for the $G$ treatment compared to the $\mathrm{C}$ treatment, in the first and second year following vegetation manipulation. At the third year following vegetation manipulation, no significant difference in total cover remained between the three treatments (significant interaction term, Table 2; Fig. 1c).

The CWM for nitrogen fixation did, overall, not change through time. However, when contrasting the three treatments, the CWM for nitrogen fixation decreased in the first year following vegetation manipulation in the $\mathrm{L}$ treatment, resulting in a significantly lower value for the $\mathrm{L}$ treatment compared to the $\mathrm{C}$ and $\mathrm{G}$ treatments in the first 2 years following vegetation manipulation. However, in the last year, no significant difference remained in the CWM for nitrogen fixation among the three treatments (Table 2; Fig. 1d). A comparable pattern was observed for the CWM of graminoid morphology, with an initial decrease for the $\mathrm{G}$ treatment compared to the $\mathrm{C}$ and $\mathrm{L}$ treatments in the first year following vegetation manipulation, and a gradual recovery of the CWM of graminoid morphology through time. Interestingly, unlike the CWM for nitrogen fixation, the CWM of graminoid morphology showed a gradual overall increase through time, independent of treatment (Table 2; Fig. 1e). The CWM for clonality showed the same patterns as the CWM for graminoid morphology, although the differences between the $G$ treatment on the one hand and the $C$ and $L$ treatments on the other hand were less pronounced (Table 2; Fig. 1f).

An overview of the seven EGs defined by Helsen et al. [39] is presented in Table 1. Group names are based on the groups' trait composition: megaphanerophytes (group 1), forest/shrub species (group 2), orchids (group 3), small grassland herbs (group 4), large herbs and grasses (group 5), sedges and shallow soil specialists (group 6) and annuals (group 7). Since too few species of EG 3 (orchids) were present in this study, it was removed from further analyses. Comparing the treatment functional groups (graminoids and legumes) with the EGs revealed that most legumes belong to EG 4 (small grassland

Table 2 Parameter estimates of the performed repeated measures linear mixed models on diversity measures and CWMs

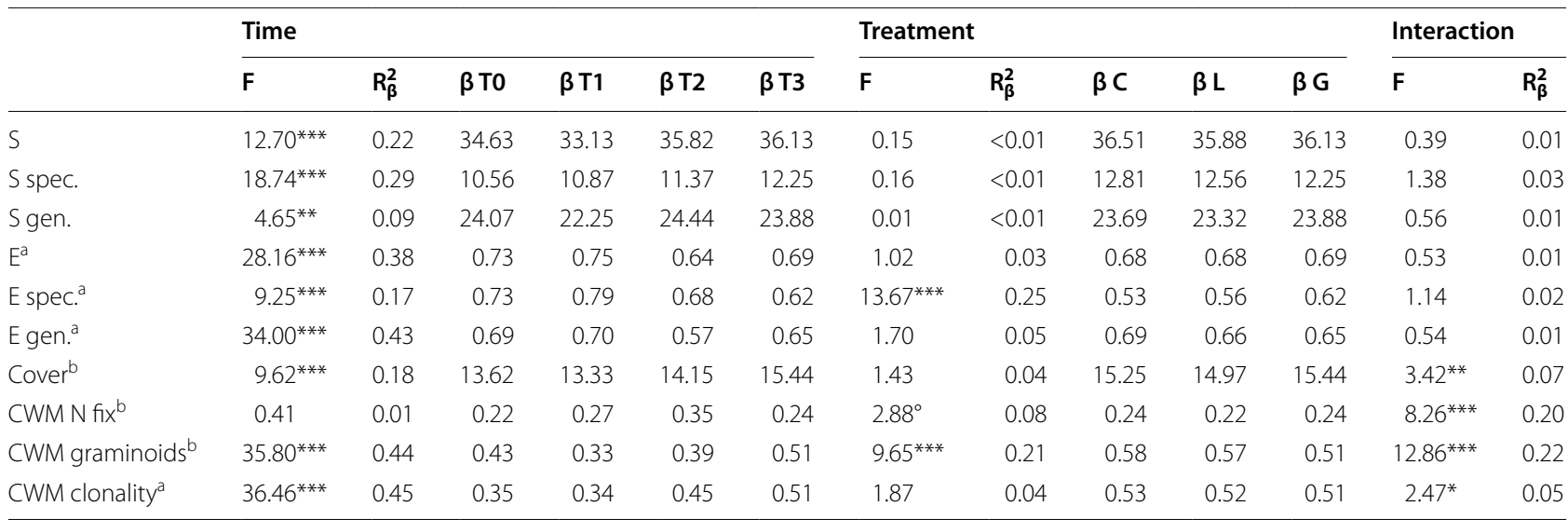

Beta-coefficient, test statistic and semi-partial $R_{\beta}^{2}$ given for time, treatment and the interaction term

$S$ species richness, $E$ Pielou's evenness, $C W M$ community weighted mean, $T$ time since treatment (year), $C$ control treatment, $L$ legumes treatment, $G$ graminoids treatment

${ }^{\circ} 0.10 \geq P>0.05 * 0.05 \geq P>0.01 ; * * 0.01 \geq P>0.001 ; * * 0.001 \geq P$

a Squared transformation

b Square root transformation 

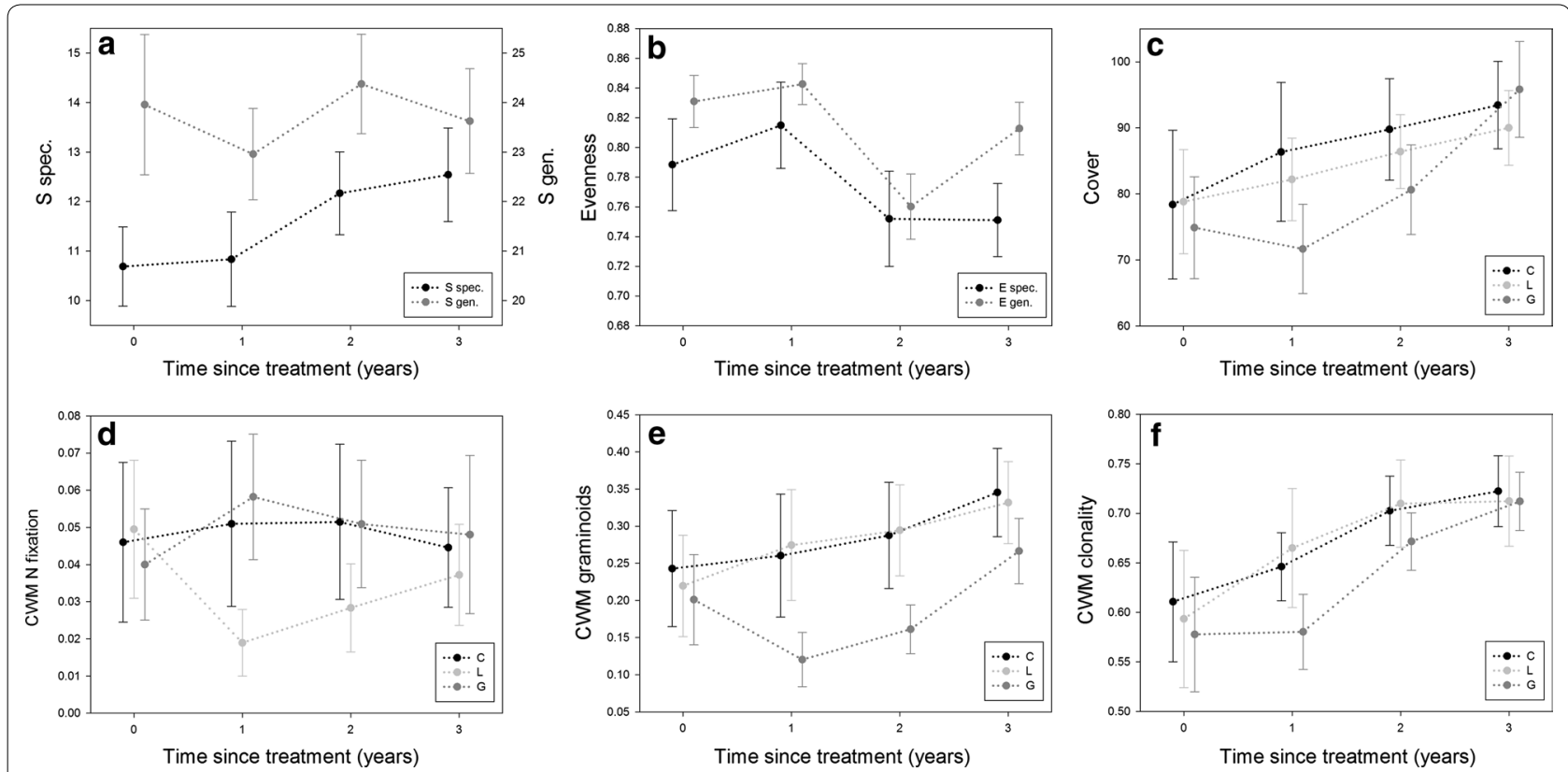

Fig. 1 Change in species richness, evenness, total cover and CWM for several functional plant traits through time. Changes through time given for: a species richness, b Pielou's evenness, c total cover, $\mathbf{d}$ CWM for nitrogen (N) fixation, e CWM for graminoids, $\mathbf{f} C W M$ for clonality. For $\mathbf{a}$ and $\mathbf{b}$ specialist species in black, generalist species in grey. For c-f C control black, L legumes light grey, G graminoids dark grey. Overall mean and $95 \%$ confidence intervals are presented for each time point

herbs), and to lesser extent to EG 7 (annuals). Graminoids occur mainly in EGs 4 (small grassland herbs), 5 (large herbs and grasses) and 6 (sedges and shallow soil specialists), with also three species in EG 7 (annuals) (Additional file 2). Consequently, the RMLMMs for EG species richness and cover were only performed twice for these EGs (i.e., 4, 5, 6 and 7), with and without the treatment species (graminoids and legumes). For EGs 1 and 2 , the RMLMMs were performed once for both species richness and cover (Table 3 ).

Five of the six studied EGs were observed to change through time, both in terms of species richness and total cover, with a decrease of megaphanerophytes and annuals, and an increase in species richness of small grassland herbs and sedges and shallow soil specialists. The pattern for forest/shrub species was less pronounced, with a small increase in species richness, but a decrease in total cover through time. Large herbs and grasses were unaffected by time, both in terms of species richness and total cover (Table 3). Species richness of megaphanerophytes and large herbs and grasses furthermore differed among the treatments, with higher richness of megaphanerophytes, but lower richness of large herbs and grasses for the $\mathrm{L}$ treatment and higher richness of large herbs \& grasses for the $\mathrm{G}$ treatment compared to the $\mathrm{C}$ treatment (Table 3; Fig. 2a). Most interestingly, these patterns remained significant after excluding the treatment species from the dataset (graminoids and legumes) (Table 3; Fig. 2b). Total cover of large herbs and grasses was lower for the $\mathrm{G}$ treatment compared to the $\mathrm{C}$ and $\mathrm{L}$ treatment in the second and third year following vegetation manipulation when including the treatment species (significant interaction term, post hoc results not shown). Total cover of sedges and shallow soil specialists was also significantly lower for the $G$ treatment compared to the $\mathrm{C}$ and $\mathrm{L}$ treatment (significant treatment effect, Table 3). However, these differences disappeared when excluding the treatment species (Table 3).

Species replacement of graminoids, based on both species presence-absence and cover, during the first and last year of the experiment was not significantly different among treatments (Table 4). Similarly, species replacement of legumes between the first and last year of the experiment was similar among the three treatments (Table 4).

\section{Discussion}

\section{General assembly patterns}

Changes in species richness and functional group composition through time observed in the $\mathrm{C}$ treatment can be interpreted as the natural assembly patterns in the studied grasslands. This natural assembly process is characterized by the replacement of generalist by specialist species and an increase in total vegetation cover through time. These results largely confirm the assembly patterns 


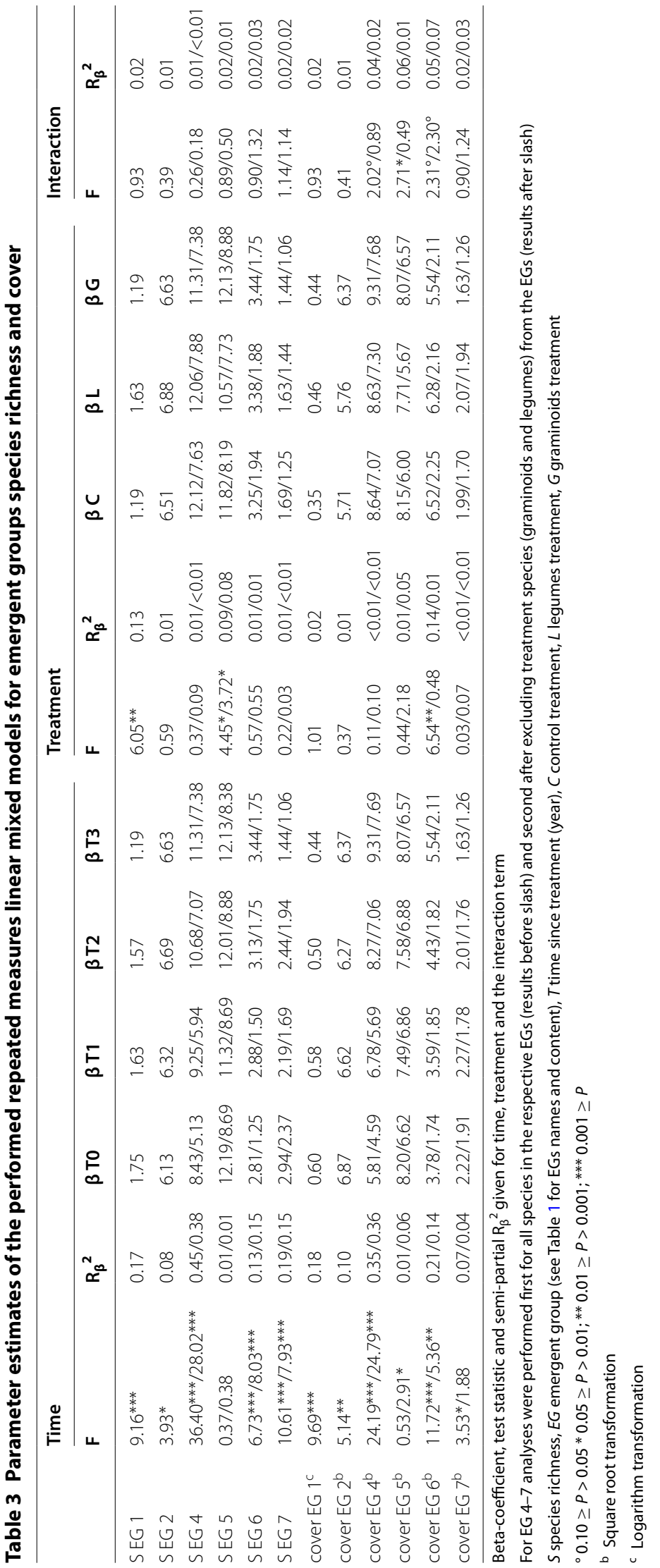



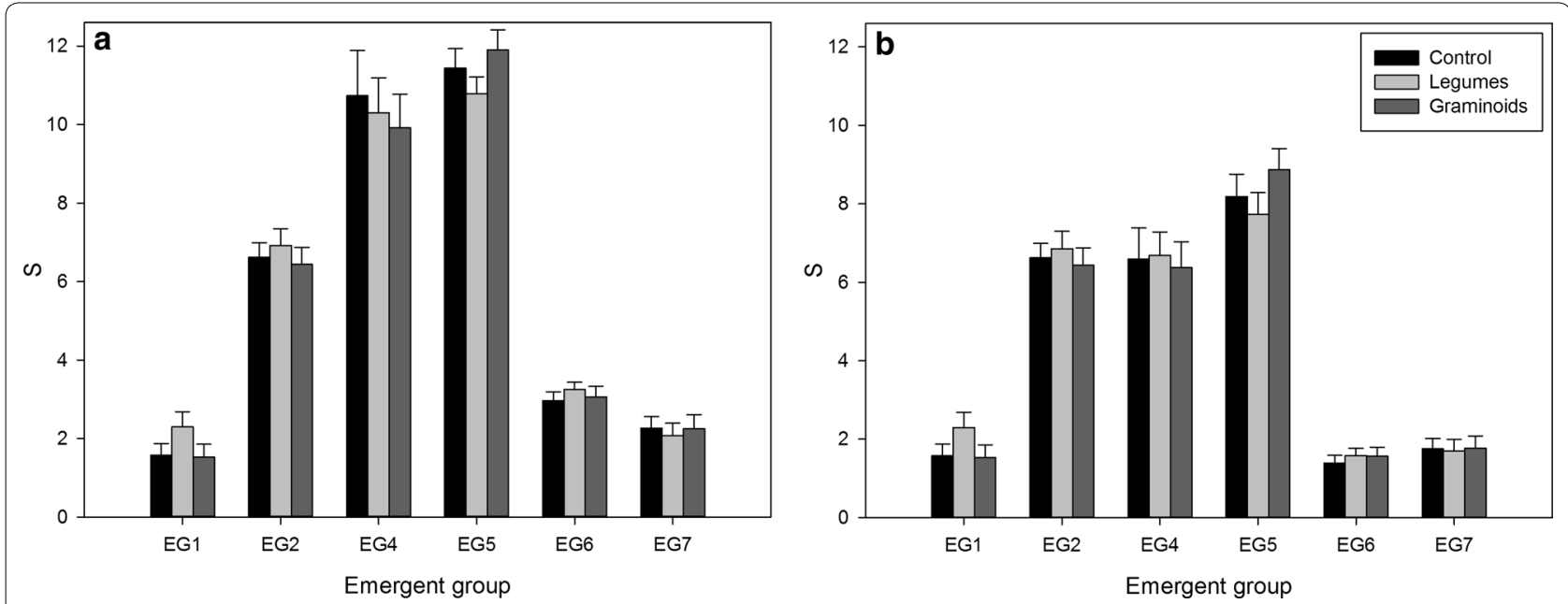

Fig. 2 Differences in species richness for the different emergent groups between the three treatments. a Bar plots given for all present species, $\mathbf{b}$ bar plots given for all species excluding treatment species (graminoids and legumes). Differences are given for the different treatments separately (C control black, L legumes light grey, G graminoids dark grey). Overall mean and $95 \%$ confidence intervals are presented for each emergent group. EG1 megaphanerophytes, EG2 forest/shrub species, EG4 small grassland herbs, EG5 large herbs and grasses, EG6 sedges and shallow soil specialists, EG7 annuals

Table 4 Parameter estimates of the performed linear mixed models for species replacement

\begin{tabular}{llllll}
\hline & \multicolumn{4}{l}{ Treatment } \\
\cline { 2 - 6 } & $\mathbf{F}$ & $\mathbf{R}_{\boldsymbol{\beta}}^{\mathbf{2}}$ & $\boldsymbol{\beta C}$ & $\boldsymbol{\beta} \mathbf{L}$ & $\boldsymbol{\beta} \mathbf{G}$ \\
\hline $\mathrm{G}^{\mathrm{a}} \mathrm{R}_{\text {rel }}$ (cover) & 0.12 & 0.003 & 0.36 & 0.40 & 0.38 \\
$\mathrm{G} \mathrm{R}_{\text {rel }}$ (presabs) & 0.25 & 0.006 & 0.41 & 0.44 & 0.39 \\
$\mathrm{~L}^{\mathrm{a}} \mathrm{R}_{\text {rel }}$ (cover) & 0.01 & 0.001 & 0.17 & 0.16 & 0.17 \\
$\mathrm{~L} \mathrm{R}_{\text {rel }}$ (presabs) & 0.25 & 0.006 & 0.17 & 0.13 & 0.17 \\
\hline
\end{tabular}

Beta-coefficient, test statistic and semi-partial $R_{\beta}^{2}$ given for treatment $G$ graminoids, $L$ legumes, ${ }^{a} R_{\text {rel }}$ relativized abundance replacement, $R_{\text {rel }}$ relativized species replacement, $C$ control treatment, presabs presence-absence

* $0.05 \geq P>0.01 ; * * 0.01 \geq P>0.001 ;{ }^{* * *} 0.001 \geq P$

previously observed through a chronosequence approach in similar dry semi-natural grasslands [39]. At the functional trait level, the assembly patterns also partly confirmed the previous results of Helsen et al. [39]. However, opposite to the chronosequence study, the number of forest/shrub species showed a small increase, and annuals a strong decrease in species numbers through time in this study. Large herbs and grasses were found to remain relatively constant through time in this study, while a decrease in richness was found for these groups in the chronosequence study [39]. These differences might be caused by the smaller time scale in this study.

\section{Species removal effects on non-treatment species}

The initial treatments resulted in changes in the functional trait set of the grassland communities in the first years following manipulation, with, for the G treatment, a reduction of total cover, graminoid species richness and associated cover of the emergent groups that mainly consist of graminoid species. In the L treatment, manipulation initially resulted in a reduction of $\mathrm{N}$ fixating species, but had no significant effect on total cover.

Interestingly, species richness was not affected by treatment, with similar levels of both specialist and generalist species across treatments. This is in accordance with other priority effect experiments, where species richness was found to converge, independent of initial differences in species richness and treatment [10, 32]. Both the G and $\mathrm{L}$ treatments nevertheless affected species composition. More specifically, the removal of graminoids resulted in a small, but nonetheless significant increase in the number of species in EG 5 (large herbs and grasses). This is in accordance with our (inhibitory) niche preemption hypothesis, with species with similar niches as the removed graminoids benefitting from the treatment $[26,28]$. In other words, the removal of large competitive grasses resulted in a small increase of large competitive herbs, likely through colonization. The absence of a similar pattern for EGs 4 and 6, which also contain many graminoids, is likely caused by the fast recovery of graminoids species in these grasslands, well before other species can colonize due to reduced within-niche competition (see the 'species removal effects on treatment species' discussion section further). Alternatively, it could be argued that the inhibitory competitive priority effects are less pronounced within these EGs, which are characteristic of high stress-low competition communities. It has 
indeed been suggested that the strength of direct (inhibitory niche preemption) priority effects are dependent on soil nutrient levels, implying that priority effects in experimental studies (using optimal nutrient concentrations) are likely much stronger than those occurring in natural (nutrient poor) communities [10,36]. Since EG 5 mainly consists of relatively competitive species, this could explain the stronger effect of species removal for this specific group. Indeed, all else being equal, direct inhibitory niche preemption priority effects are expected to be more pronounced for competitive species that produce much biomass [24, 36]. Since soil legacies are strongly species-specific, we also cannot exclude the possibility of differential facilitative or inhibitory soil legacy effects of graminoid species, indirectly promoting the establishment of species of EG $5[21,22]$.

In accordance with our hypothesis, legume removal did not affect the species richness of EG 4 (or 7), which contain all legume species, but resulted in changes in unrelated functional groups (decrease of the number of large herbs and grasses, and an increase of megaphanerophytes). This suggests the occurrence of niche modification effects of legumes after their removal. As discussed earlier, the low overall competitive abilities of the legumes present in these grasslands (Additional file 2) likely explain why competitive exclusion (niche preemption) is limited within this functional group. Previous research has also shown that legumes do often not exert persistent inhibitory priority effects through sizeasymmetric competition, and often facilitate higher biomass production of functionally different co-occurring plant species through nitrogen enrichment of the soil (facilitation) $[19,49]$. This facilitative niche modification effect can be especially effective for plants growing in nutrient poor grasslands, as is the case in this study. The removal of legumes in the $\mathrm{L}$ treatment likely resulted in open patches with increased nitrogen availability. Megaphanoreophyte seedlings seem to be better at establishing at these former legume sites, suggesting facilitative soil legacies through nitrogen enrichment [21]. In this scenario, the observed decrease in species of EG 5 might be partly caused by the decreased competitive success of large (herbs and grasses) against megaphanerophytes. Alternatively, the absence of legumes might have resulted in a lower overall availability of nitrogen in the community, an effect that will most strongly inhibit the growth of species that are not adapted to nutrient poor conditions, such as those of EG 5. Indeed, this EG mainly contains generalist species adapted to fast growth and relatively nutrient rich soils (Table 1; [39]). The positive effect on megaphanerophytes on the other hand might then suggest that legumes have a negative effect on tree and shrub seedlings through inhibitory niche modification effects, independent of their effect on nitrogen availability.

\section{Species removal effects on treatment species}

In this experiment, both graminoid and legume removal was after 4 years almost completely compensated by the recolonization of graminoids and legumes, respectively, strongly suggesting that niche processes shape community assembly and priority effects in certain semi-natural grassland systems, as previously argued by Helsen et al. [31]. Although this was largely expected for graminoids, we did not expect similar patterns to occur for legumes. More surprisingly, the species replacement rates among the treatments show that this recolonization is effectuated by largely the same set of species as those that were removed. This suggests that niche preemption through size-asymmetric competition is likely only partly driving these patterns, since we would have expected some levels of species replacement (within functional groups) in this case. Likely, the observed patterns are also partly driven by localized soil legacies that promote the colonization of the same species (facilitative), or prevent the colonization of other species (inhibitory legacy effects acting within a functional group). Although some studies demonstrated that within species plant-soil feedbacks can be inhibitory $[21,35]$, other studies have indeed shown that many species exhibit weaker inhibitory, or even facilitative plantsoil feedbacks upon conspecifics compared to plant-soil feedbacks upon other species [23, 34].

The observed patterns can, however, also be at least partly explained by other confounding factors. Since (dead) belowground biomass of the treatment species was not actively removed, possible priority effects of these species might have been much stronger than would have been the case after complete removal of the species. Indeed, inhibitory size-asymmetric competitive priority effects are not solely driven by aboveground biomass, but can also remain strong when aboveground biomass is periodically removed through mowing [19]. Furthermore, since all treatments were performed in relatively small plots within a larger grassland, the removed species are also present in the direct vicinity of the treatment plot, enhancing the chances of recolonization of the plot by the same species set, thus deflating replacement rates. This effect might have been especially strong for legumes, since only a relatively small number of species was present in these grasslands. Most of the graminoids were furthermore strongly clonal (Fig. 1e, f), also allowing quick clonal recolonization of the plot by ramets present at the vicinity of the plot border. In conclusion, we believe that soil legacies likely resulted in reduced levels of species replacement, but that this affect was likely not as strong as suggest by the species replacement results. 


\section{Treatment effects through time}

Although changes in the EG compositions across the different treatments persisted after 4 years (no significant interaction between time and treatment), we did also observe a fast recovery of the number and composition of both legumes and graminoids during the same time span. Contrary to our predictions, this suggests that the effect of specific functional group removal during grassland assembly does not result in alternative assembly pathways, through newly enforced priority effects of the secondary colonized species. These results more likely suggest that soil legacies result in, at least partial, maintenance of initial priority effects after species removal. This, in turn, allows the fast recolonization of the removed species, with only limited changes in overall species composition. These results are partly in agreement with the study of Plückers et al. [37], where initial differences in species richness and functional composition (forbs, grasses and legumes) through differential seeding, became very small after 4 years, with communities seemingly converging toward similar species richness and functional composition.

\section{Conclusions}

In this study, we explored how priority effects within and among functional groups affect community assembly during natural plant community assembly. More specifically, our results show that, in a low nutrient, (semi-)natural grassland system, inhibitory priority effects acting through niche preemption can be slightly relieved by species removal. However, this relief depended on the competitive ability of the removed species, with relief only observed for more competitive grasses and herbs, but not for smaller grassland specialists. Although competition effects acting within functional groups (niche preemption) were observed for graminoids, they do not seem to apply to legumes. Indeed, the removal of legumes mainly affected functionally unrelated generalist species and megaphanerophytes, likely through the facilitative niche modification effects of nitrogen fixation after legume removal [14].

On the other hand, species removal was, contrary to our expectations, almost completely compensated by recolonization of the same species set, suggesting that the net community composition effects of species (group) removal is rather limited in this natural system. This additionally suggests that soil legacies are, at least up to a certain extent, important drivers of assembly patterns during natural grassland assembly. We can expect that, in the context of ecological restoration, if unwanted species get established, it might prove difficult to neutralize their effect on the community assembly outcome, since their imposed priority effects might act long after their removal through imposed soil legacies [16].

\section{Additional files}

Additional file 1. Overview of the selected traits, used for the delineation of the emergent groups. Description, scale and main data sources are given for every trait.

Additional file 2. Overview of the species list. Species are defined as generalist (g) of specialist (s), and subdivided in seven emergent groups (EGs). Group numbers correspond to the emergent groups described in Table 1. The treatment column indicates what species are graminoids $(G)$ and legumes $(\mathrm{L})$.

\begin{abstract}
Abbreviations
${ }^{a} \mathrm{R}_{\text {rel }}$ : relativized abundance replacement; C: control treatment; CWM: community weighted mean; E: Pielou's evenness; EG: emergent group; G: graminoids treatment; L: legumes treatment; LMM: linear mixed model; REML: restricted maximum likelihood; RMLMM: repeated measures linear mixed model; $R_{\text {rel: }}$ relativized species replacement; $S$ : species richness.
\end{abstract}

\section{Authors' contributions}

$\mathrm{KH}$ performed fieldwork and statistical analyses and drafted the manuscript. $\mathrm{OH}$ and $\mathrm{MH}$ participated in the design of the study and helped to draft the manuscript. All authors read and approved the final manuscript.

\section{Author details \\ ${ }^{1}$ Plant Conservation and Population Biology, Department of Biology, Uni- versity of Leuven, Arenbergpark 31, 3001 Heverlee, Belgium. ${ }^{2}$ Department of Biology, Norwegian University of Science and Technology, Høgskoleringen 5, 7034 Trondheim, Norway. ${ }^{3}$ Division Forest, Nature and Landscape Research, Department Earth and Environmental Sciences, University of Leuven, Celesti- jnenlaan 200E, 3001 Heverlee, Belgium.}

\section{Acknowledgements}

Thanks goes out to Stijn Cornelis, Pieter Gijbels, Krista Takkis and Kasper Van Acker for assistance in the field.

\section{Availability of data and material}

The full plots $x$ species dataset supporting the results of this article is available from the Dryad Digital Repository: http://dx.doi.org/10.5061/dryad.7s5s4.

\section{Competing interests}

The authors declare that they have no competing interests.

\section{Funding}

This research was funded by the Flemish Fund for Scientific Research (FWO). However, the manuscript was written while K.H. held a research grant of the University of Leuven (PDMK/13/093).

Received: 31 July 2015 Accepted: 13 April 2016

Published online: 26 April 2016

\section{References}

1. Clements FE. Plant succession: an analysis of the development of vegetation. Carnegie Washington: Institution of Washington; 1916.

2. Chase JM. Community assembly: when should history matter? Oecologia 2003:136:489-98.

3. Brudvig LA. The restoration of biodiversity: where has research been and where does it need to go? Am J Bot. 2011:98:549-58.

4. McCune B, Allen TFH. Will similar forests develop on similar sites? Can J Bot. 1985;63:367-76.

5. Fastie CL. Causes and ecosystem consequences of multiple pathways of primary succession at Glacier Bay, Alaska. Ecology. 1995;76:1899-916.

6. Honnay O, Verhaeghe W, Hermy M. Plant community assembly along dendritic networks of small forest streams. Ecology. 2001;82:1691-702. 
7. Gleason HA. Further views on the succession-concept. Ecology. 1927:8:299-326.

8. Diamond JM. Assembly of species communities. In: Cody ML, Diamond $J M$, editors. Ecology and evolution of communities. Cambridge: Harvard University Press; 1975.

9. Young TP, Chase JM, Huddleston RT. Community succession and assembly Comparing, contrasting and combining paradigms in the context of ecological restoration. Ecol Restor. 2001;19:5-18.

10. Ejrnæs R, Bruun HH, Graae BJ. Community assembly in experimental grasslands: suitable environment or timely arrival? Ecology. 2006:87:1225-33.

11. Baeten L, Hermy M, Verheyen K. Environmental limitation contributes to the differential colonization capacity of two forest herbs. J Veg Sci. 2009;20:209-23.

12. Van der Putten WH, Bardgett RD, Bever JD, Bezemer TM, Casper BB, Fukami T, et al. Plant-soil feedbacks: the past, the present and future challenges. J Ecol. 2013;101:265-76.

13. Fukami T, Nakajima M. Complex plant-soil interactions enhance plant species diversity by delaying community convergence. J Ecol. 2013;101:316-24.

14. Fukami T. Historical contingency in community assembly: integrating niches, species pools, and priority effects. Annu Rev Ecol Evol Syst. 2015:46:1-23.

15. Weiner J. Asymmetric competition in plant populations. Trends Ecol Evol. 1990;5:360-4

16. Grman E, Suding KN. Within-year soil legacies contribute to strong priority effects of exotics on native California grassland communities. Restor Ecol. 2010;18:664-70.

17. Cuddington K. Legacy effects: the persistent impact of ecological interactions. Biol Theory. 2011;6:203-10.

18. Hubbell SP. The unified neutral theory of biodiversity and biogeography. Princeton: Princeton University Press; 2001.

19. Körner C, Stöcklin J, Reuther-Thiébaud L, Pelaez-Riedl S. Small differences in arrival time influence composition and productivity of plant communities. New Phytol. 2008;177:698-705.

20. Collinge SK, Ray C. Transient patterns in the assembly of vernal pool plant communities. Ecology. 2009;90:3313-23.

21. van de Voorde TFJ, van der Putten WH, Bezemer MT. Intra- and interspecific plant-soil interactions, soil legacies and priority effects during old-field succession. J Ecol. 2011:99:945-53.

22. Hawkes CV, Kivlin SN, Du J, Eviner VT. The temporal development and additivity of plant-soil feedback in perennial grasses. Plant Soil. 2013;369:141-50.

23. Baxendale C, Orwin KH, Poly F, Pommier T, Bardgett RD. Are plantsoil feedback responses explained by plant traits? New Phytol. 2014;204:408-23.

24. Cleland EE, Esch E, Mckinney J. Priority effects vary with species identity and origin in an experiment varying the timing of seed arrival. Oikos. 2015:124:33-40.

25. Tan J, Pu Z, Ryberg WA, Jiang L. Species phylogenetic relatedness, priority effects, and ecosystem functioning. Ecology. 2012;93:1164-72.

26. Vannette RL, Fukami T. Historical contingency in species interactions: towards niche-based predictions. Ecol Lett. 2014;17:115-24.

27. Fargione J, Brown CD, Tilman D. Community assembly and invasion: an experimental test of neutral versus niche processes. Proc Natl Acad Sci USA. 2003;100:8916-20.

28. Mwangi PN, Schmitz M, Scherber C, Roscher C, Schumacher J, SchererLorenzen $\mathrm{M}$, et al. Niche pre-emption increases with species richness in experimental plant communities. J Ecol. 2007;95:65-78.

29. Price JN, Pärtel M. Can limiting similarity increase invasion resistance? A meta-analysis of experimental studies. Oikos. 2013;122:649-56.

30. Fukami T, Bezemer MT, Mortimer SR, Putten WH. Species divergence and trait convergence in experimental plant community assembly. Ecol Lett. 2005:8:1283-90.
31. Helsen K, Hermy M, Honnay O. Trait but not species convergence during plant community assembly in restored semi-natural grasslands. Oikos. 2012;121:2121-30.

32. Roscher C, Schumacher J, Gerighausen U, Schmid B. Different assembly processes drive shifts in species and functional composition in experimental grasslands varying in sown diversity and community history. PLoS One. 2014;9:e101928.

33. Grime JP. Trait convergence and trait divergence in herbaceous plant communities: mechanisms and consequences. J Veg Sci. 2006;17:255-60.

34. Kardol P, Cornips NJ, van Kempen MML, Bakx-Schotman JMT, van der Putten WH. Microbe-mediated plant-soil feedback causes historical contingency effects in plant community assembly. Ecol Monogr. 2007;77:147-62

35. Harrison KA, Bardgett RD. Influence of plant species and soil conditions on plant-soil feedback in mixed grassland communities. J Ecol. 2010:98:384-95.

36. Kardol P, Souza L, Classen AT. Resource availability mediates the importance of priority effects in plant community assembly and ecosystem function. Oikos. 2013;122:84-94.

37. Plückers C, Rascher U, Scharr H, Von Gillhaussen P, Beierkuhnlein C, Temperton VM. Sowing different mixtures in dry acidic grassland produced priority effects of varying strength. Acta Oecol. 2013:53:110-6.

38. Helsen K, Hermy M, Honnay O. Data from: a test of priority effect persistence in semi-natural grasslands through the removal of plant functional groups during community assembly. Dryad Digit Repos. 2016. doi:10.5061/dryad.7s5s4.

39. Helsen K, Hermy M, Honnay O. Spatial isolation slows down directional plant functional group assembly in restored semi-natural grasslands. J Appl Ecol. 2013;50:404-13.

40. Weiher E, Werf A, Thompson K, Roderick M, Garnier E, Eriksson O. Challenging Theophrastus: a common core list of plant traits for functional ecology. J Veg Sci. 1999;10:609-20.

41. Díaz S, Lavorel S, de Bello F, Quétier F, Grigulis K, Robson TM. Incorporating plant functional diversity effects in ecosystem service assessments. Proc Natl Acad Sci USA. 2007:104:20684-9.

42. Fitter A, Peat H. The ecological flora database. J Ecol. 1994;82:415-25.

43. Klotz S, Kühn I, Durka W. BIOLFLOR_Eine Datenbank zu biologischökologischen Merkmalen der Gefäßpflanzen in Deutschland. Bonn: Bundesamt für Naturschutz, Schriftenreihe für Vegetationskunde 38; 2002.

44. Lambinon J, De Langhe J, Delvosalle L, Duvigneaud J. Flora van België, het Groothertogdom Luxemburg, Noord-Frankrijk en de aangrenzende gebieden (Pteridofyten en Spermatofyten). Meise: Nationale plantentuin van België; 1998.

45. van Landuyt W, Hoste I, Vanhecke L, Van den Bremt P, Vercruysse W, De Beer D. Atlas van de flora van Vlaanderen en het Brussels Gewest. Brussel: Instituut voor natuur- en bosonderzoek, Nationale Plantentuin van België \& Flo.Wer; 2006

46. Podani J, Schmera D. A new conceptual and methodological framework for exploring and explaining pattern in presence-absence data. Oikos. 2011;120:1625-38.

47. Podani J, Ricotta C, Schmera D. A general framework for analyzing beta diversity, nestedness and related community-level phenomena based on abundance data. Ecol Complex. 2013;15:52-61.

48. Edwards $L$, Muller KE, Wolfinger RD, Qaqish BF, Schabenberger O. An $R^{2}$ statistic for fixed effects in the linear mixed model. Stat Med. 2008;27:6137-57.

49. Von Gillhaussen P, Rascher U, Jablonowski ND, Plückers C, Beierkuhnlein C, Temperton VM. Priority effects of time of arrival of plant functional groups override sowing interval or density effects: a grassland experiment. PLoS One. 2014;9:e86906. 